\title{
RELAÇÃO DE APEGO ENTRE CRIANÇAS INSTITUCIONALIZADAS QUE VIVEM EM SITUAÇÃ̃O DE ABRIGO
}

\author{
Diuvani Tomazoni Alexandre* \\ Mauro Luís Vieira
}

\begin{abstract}
RESUMO. Este estudo teve como objetivo identificar a relação de apego entre crianças institucionalizadas que vivem em situação de abrigo. Participaram do estudo quatorze crianças de ambos os sexos, com idades compreendidas entre 3 e 9 anos. Os dados foram coletados através da técnica de observação do sujeito focal. Os principais resultados foram: a) os irmãos mais velhos demonstraram-se responsivos às solicitações de afeto e cuidado em relação aos irmãos mais novos; foi registrada interação significativa entre as meninas mais velhas com os meninos mais novos; b) a brincadeira social mostrou ser uma situação favorável ao estabelecimento das interações afetivas; c) a imagem da família aparece representada pela figura materna. Conclui-se que, na falta de um adulto significativo, crianças em situação de abrigo acabam formando relações de apego umas com as outras e que a rede de apoio social representa um importante aspecto na resiliência destas crianças.
\end{abstract}

Palabras clave: apego, criança institucionalizada, interação criança-criança.

\section{ATTACHMENT RELATIONSHIPS AMONG INSTITUTIONALIZED CHILDREN LIVING IN A SHELTER SITUATION}

\begin{abstract}
The present study had as propose to identify the attachment relationships among institutionalized infants. Fourteen infants, living in a shelter, of both sexes, aged between 3 and 9 years old, took part in this study. For the recording of the behaviors, the observational technique known as "focal-subject" was used. The main results permit us to identify: a) eldest brothers demonstrate responsive affect and care solicitations to the youngest brothers; it was registered significant interaction among older girls and younger boys; b) the play social showed to be a favorable situation for the settlement of the affective interactions; c) family image appears represented by the mother figure. Therefore, it is concluded that, when the absence of a significant adult occurs, children living in a shelter situation can development attachment relationships among themselves and that a social support network represents an important aspect in the resilience of these children.
\end{abstract}

Key words: attachment, institutionalized child, child-child interaction.

A Teoria do Apego evidencia a importância da ligação emocional que se desenvolve entre o bebê e seu "cuidador", para orientar o desenvolvimento afetivo, cognitivo e social da criança. A partir de uma perspectiva etológica, Bowlby (1990) constatou que os bebês, assim como os pássaros, também apresentam um "período sensível", em que se encontram mais dispostos a formar vínculo com suas mães. Dessa maneira, eles revelam esse vínculo (chamado apego) através do comportamento (sorrir, chorar, sugar o polegar, olhar em direção à mãe, buscar proximidade, contato físico) destinado a atrair a mãe para perto deles (recém-nascidos), ou levá-los (quando maiores) em direção a suas mães.

Dizer que uma criança tem apego por alguém significa que ela está fortemente disposta a buscar proximidade e contato com uma figura específica, principalmente quando está cansada, assustada ou doente. Para isso, considerou-se o apego uma ligação contínua e íntima, apresentada pela criança em relação à mãe ou cuidador; enquanto o comportamento de apego é qualquer forma de comportamento que uma criança comumente adota para conseguir e/ou manter uma proximidade com algum outro indivíduo

* Docente de Psicologia do Desenvolvimento e da Aprendizagem do Instituto Cenecista Fayal de Ensino Superior de Itajaí, SC. Pedagoga, mestre em Psicologia pela Universidade Federal de Santa Catarina.

\# Docente do Departamento de Psicologia da Universidade Federal de Santa Catarina, SC. Doutor em Psicologia Experimental pela Universidade de São Paulo, SP e pós-doutorado pela Dalhousie University (Canadá). 
claramente identificado, por exemplo, a mãe. Assim, a característica essencial comum entre apego e comportamento de apego é que dois parceiros tendem a manter-se próximos um do outro (Klaus, Kennell \& Klaus, 2000).

Um fator importante no comportamento de apego é a intensidade da emoção que o acompanha. Essa emoção surge conforme acontece a relação entre a pessoa apegada e a figura de apego. A partir dessas considerações, Lebovici (1987) reforça que, se tudo está bem, há satisfação e um senso de segurança; porém, se esta relação está ameaçada, existem ansiedade e angústia. Caso ocorra uma ruptura, há dor e depressão. No caso de privação materna, seja este afastamento de ordem física ou emocional, muitas são as consequiências, tanto de ordem física quanto intelectual e social, podendo, inclusive, protagonizar o aparecimento de enfermidades físicas e mentais (Oppenheim, Koren \& Sagi, 2001).

Desta forma, uma criança que tem pais afetivos e vive em um lar bem-estruturado, no qual encontra conforto e proteção, consegue desenvolver um sentimento de segurança e confiança em si mesma e em relação àqueles que convivem com ela (Bowlby,1990). Do contrário, conforme o autor, se uma criança cresce em situação irregular (afastada da vida familiar), pressupõe-se que sua base de segurança tende a desaparecer, o que pode prejudicar suas relações com os outros, havendo, assim, prejuízos nas demais funções de seu desenvolvimento.

Outro aspecto importante é que o apego é a base para a identificação e a determinação de relações duradouras e mútuas, que são a base para a formação de uma rede de apoio social. A rede de apoio social origina-se das relações de apego iniciais da criança e da disponibilidade dos pais em atender às suas necessidades (Tyler, 1984). A esse respeito, Newcomb (1990) sustenta que a rede de apoio social começa a se formar quando a criança se expande socialmente, relacionando-se com pessoas não familiares, como aqueles com quem convive nas creches, por exemplo. Aponta, ainda, que a rede de apoio é dinâmica e construída ao longo da vida de um indivíduo e que pode proteger a pessoa de efeitos negativos causados por adversidades. Tal rede corresponde à oportunidade de aprofundamento dos relacionamentos, permitindo que a criança obtenha melhores condições para seu desenvolvimento, tornando-se, dessa forma, uma criança resiliente, ou seja, capaz de enfrentar as situações adversas, ajustando-se a elas com mais facilidade (Tyler, 1984).

Do ponto de vista social, o estudo sobre resiliência é de suma importância, uma vez que representa a possibilidade de se trabalhar com os problemas experimentados pelas pessoas que se encontram em condições desfavoráveis, como, por exemplo, pobreza, desemprego, envolvimento com drogas, e, principalmente, com crianças que crescem no abandono, longe da convivência familiar (Rutter, 1997). Os autores que apontam a resiliência como uma adaptação positiva relatam que algumas pessoas, vivendo em ambientes desfavoráveis, revelam uma capacidade notável para se desenvolver de forma saudável (Infante, 2001; Rutter, 1997). Em síntese, uma segura relação de apego reduz os efeitos das adversidades e auxilia na resiliência.

Ao falarmos da criança institucionalizada, observamos que, mesmo recebendo cuidados alimentares, higiênicos e médicos, ela caminha tardiamente, demora a falar e tem dificuldade para estabelecer ligações significativas (Rizzini, 1995). A autora assinala que abandonar uma criança ou enviá-la para um abrigo é privá-la de ter uma família, onde existem intimidade e cumplicidade. Não é possível relacionar-se assim em abrigos, pois há uma proporção grande de crianças em relação a adultos. Assim, o eventual afeto recebido dos funcionários tem que ser dividido entre as crianças.

Desta forma, observa-se que, mesmo diante das inúmeras tentativas legislativas de amparo à infância (ECA, 1990), a realidade apresenta lacunas não preenchidas, no que diz respeito ao abandono infantil. É essencial o entendimento de que a privação de laços afetivos durante a infância interfere no desenvolvimento saudável da criança, podendo afetar suas relações com o outro e com o meio que a cerca. A este respeito, observa Santos (2000, p. 87), "O princípio que deve nortear a ação dos que trabalham com crianças em situação de abrigo deverá ser sempre o de garantir à criança as condições necessárias para o seu pleno desenvolvimento, tanto no presente quanto no futuro".

O objetivo deste estudo consistiu em investigar se crianças abrigadas desenvolvem apego umas às outras, e se este apego pode ser semelhante ao do adulto-criança, ou seja, uma relação constituída por um vínculo afetivo e recíproco, em que os cuidadores, satisfazem as necessidades daqueles que são cuidados.

\section{MÉTODO}

\section{Amostra}

A amostra constituiu-se de 14 crianças de ambos os sexos, sendo 5 meninas e 9 meninos, com idades compreendidas entre 3 e 9 anos, atendidas em uma instituição privada que se caracteriza por "Abrigo". 
Das crianças selecionadas, algumas estão abrigadas em conseqüência do abandono, outras foram acolhidas na instituição por serem vítimas de violência doméstica (física e sexual) ou negligência parental.

$\mathrm{O}$ abrigo que atende as crianças está localizado em uma cidade do litoral de Santa Catarina. Existe desde 1989, funcionando como uma Sociedade Civil de Caráter Assistencial, sem discriminação de raça, nacionalidade ou religião, tendo como finalidade a proteção e educação da criança, com duração indeterminada e sem fins lucrativos.

Atualmente, o abrigo atende 26 crianças, com idades compreendidas entre 0 e 17 anos. De acordo com o estatuto interno da instituição, o atendimento deveria ser apenas para crianças até 12 anos, porém, se lhes for negado o direito de permanência na instituição após 12 anos, essas crianças serão novamente excluídas, acabando por viver nas ruas.

As crianças chegam a esta instituição por determinação judicial (vara da Infância e da Juventude) e pelo conselho tutelar da comarca e das comarcas circunvizinhas. São vítimas de abandono, negligência parental, violência doméstica, abuso sexual. Algumas são portadoras de HIV e de necessidades especiais.

\section{PROCEDIMENTOS}

Para a coleta de dados utilizou-se a técnica de observação do sujeito-focal e a técnica de registro de comportamento (como observar) denominada de "amostragem de tempo" (Martin \& Bateson, 1986). Os comportamentos foram registrados a cada 30 segundos. Foram realizadas 10 sessões - de 10 minutos cada uma - para cada criança, em dias alternados, durante os períodos matutino, vespertino e noturno. Todas as crianças foram observadas uma vez e, posteriormente, esse processo repetiu-se até se completarem as dez sessões. A partir da análise do material observado, identificaram-se seis categorias de comportamento:

- Contato físico: Envolve contato mútuo, de alguma parte do corpo (em geral ombros) do sujeito focal com a outra criança. No caso, o sujeito pode estar sentado ao lado da outra criança ou em pé. O contato pode durar apenas um momento ou persistir por mais de um minuto.

- Olhar: compreende um comportamento visual através do qual, a partir da posição dos olhos do sujeito e/ou posição da face, verifica-se que seu olhar está dirigido a alguma pessoa (RossettiFerreira, 1986). Esse comportamento ocorre, em geral, quando as crianças se aproximam umas das outras e quando uma criança se afasta do grupo, sendo seguida pelo olhar das que permanecem no local da observação.

- Rir: o som é variável. Uma série curta de expirações repetidas ou expirações longas. As duas fileiras de dentes ficam visíveis. Os olhos geralmente ficam bem abertos, voltados para a outra criança.

- Aproximar: a criança anda em direção a outra criança, reduzindo a distância entre elas, mas não encosta nenhuma parte do corpo na outra criança.

- Falar: inclui movimento dos lábios e expulsão de ar através deles. A língua é colocada de tal modo que são formadas palavras. Estas podem ser emitidas pelas crianças entre si ou por outras pessoas quando eram com a criança. Quando eram incompreensíveis para o observador, as verbalizações foram registradas como verbalizações indefinidas.

- Estender os braços: a criança estende os braços, em geral, para a frente, podendo também inclinar o corpo em direção a uma pessoa (mais freqüentemente em direção a outra criança). Pode encostá-los de leve em alguma parte do corpo do outro ou segurá-la com firmeza. Em geral seguram a mão ou o braço. A criança pequena levanta a mão, abrindo-a e fechando-a em seguida, em direção ao outro que pretende alcançar (às vezes fala que "quer colo").

Neste estudo, também foi utilizada a estratégia de observar várias crianças durante um curto espaço de tempo, a qual é denominada "estudo transversal" (Miller, 1998). Num diário de campo foram registrados, em dias e períodos alternados, quarenta e nove episódios das interações sociais entre as crianças, observados no ambiente de pesquisa. Registrou-se o local em que o evento ocorreu e a fala dos interlocutores. Para preservar em sigilo a identidade das crianças participantes deste estudo, foram-lhes atribuídos nomes fictícios.

\section{RESULTADOS}

Inicialmente, apresenta-se uma análise das porcentagens de ocorrência de cada categoria (comportamentos de apego) em relação ao total de intervalos considerados, acompanhada de uma análise qualitativa de episódios de interação, a fim de analisar as atividades realizadas pelas crianças e o(s) contexto(s) no(s) qual(is) tal atividade ocorreu. 
Considerando que as crianças de diferentes idades estavam sempre juntas, a análise dos dados obtidos foi feita de acordo com a faixa etária das crianças, as quais foram assim distribuídas grupo I, de crianças entre 3 e 4 anos; grupo II, de crianças entre 6 e 7 anos e grupo III, de crianças entre 8 e 9 anos.

Posteriormente, fez-se uma análise de conteúdo (Bardin, 1991) para interpretar as falas registradas no diário de campo.

\section{Porcentagem de ocorrência das categorias de comportamento de apego}

Foram consideradas para a presente análise as seguintes categorias de comportamento: contato físico, olhar, falar, aproximar, rir e estender os braços. Tais comportamentos foram apontados por Bowlby (1990) como indicadores de apego entre mãe e criança

A figura 1 demonstra as seis categorias de comportamento de apego, integrando a comparação entre os três grupos de crianças.

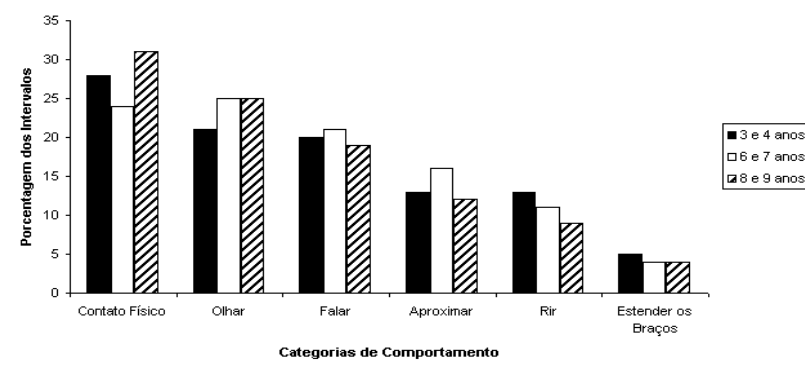

Figura 1: Porcentagem dos intervalos de observação despendido pelas crianças de diferentes idades em cada uma das categorias de comportamento registradas

Conforme se pode detectar através desta representação, entre as crianças do grupo I predominou o contato físico $(28,8 \%)$ em relação às outras categorias, incluindo pegar o parceiro pela mão ou pelo braço para levá-lo a determinado local ou permanecer de mãos dadas, puxar, tocar no ombro ou encostar os ombros, passar a mão pelos cabelos, abraçar, beijar, entre outros gestos. Também para as crianças do grupo II, o contato físico foi maior $(23,56 \%)$ do que as outras categorias e, no grupo III, apareceu com percentual de $30,86 \%$.

Com relação ao olhar, no grupo I, o percentual declina (20,85\%), em comparação ao grupo II $(25,12 \%)$ e ao grupo III $(25,43 \%)$. No entanto, para os três grupos, verificou-se que, mesmo longe do parceiro, as crianças permaneciam em contato visual, e isso permitia que as crianças se aproximassem uma das outras.
A categoria "falar" foi registrada em um percentual de $19,64 \%$ para o grupo I. Tais verbalizações incluem frases curtas chamando para as brincadeiras, como, por exemplo, "vem cá”, ou mostrando algum brinquedo "olha aqui, oh", pedindo comida as crianças mais velhas "dâ" ou "quero comer" ou ainda "comida". Também pedem colo aos irmãos mais velhos ou às meninas dos grupos II e III , falando apenas "dá colo" ou "colo” Em relação ao grupo II, a categoria "falar" apareceu com um percentual de $20,54 \%$. Neste grupo, a fala apresentouse mais ampla, com frases compostas e complexas, mas não de acordo com a norma-padrão da gramática. Assim como: "Me dá um abraço, coisa linda, porque tu és muito pequeninho e só gosta de eu”, ou então "visse, cara, ontem tu brincasse de montão e hoje nóis vai brincá outra veiz, né?”; aparecem os palavrões e xingamentos, como: "seu folgado, demônio, diabo”, entre outros. Entretanto, aparecem também palavras carinhosas como: "querido $(a)$, gosto muito de ti, maninho do coração, amigão”. A respeito da fala $(19,29 \%)$, no grupo III, observou-se a existência do diálogo. Nesse momento, as crianças passavam informações e solicitavam respostas. As palavras de duas meninas, a seguir, exemplificam este resultado:

\section{“Sofia, tu vai também no aniversário da tia Giovana”? \\ "Eu vou, Ana. Mas a tia também vai te convidar porque ela me disse que vai convidar só as meninas grandes..." \\ "É verdade, Sofia? Tu acha que a tia vai convidar eu e a Cátia"? \\ “Acho. Vai lá perguntar pra tia Katiuscia, se tu tás com medo de não ganhar convite".}

Os dados demonstram que, na relação dialógica, as crianças do grupo III compartilham experiências, ouvem umas às outras e respondem sempre às perguntas que lhes são feitas. Verificaram-se também discursos permeados de perda, frustração, ciúme, expectativa, acusação e fantasia, como, por exemplo:

\footnotetext{
"Amanhã a Clarinha vai embora. Ela vai ser adotada, né, Cátia? Eu sempre achava que ia ser adotada. Mas agora eu cresci muito, já tô com 9 anos".

"É, Sofia, a Clarinha só vai porque é nenenzinho. Nós ficamo aqui porque já crescemo. Mas aqui nós somo tudo da

As falas foram transcritas tal qual foram ouvidas pela pesquisadora.
} 
mesma família. Mas não temo mãe. Mas temo nossos irmão mesmo, né”?

"Isso, mas eu vou sair daqui quando fizer 16 anos. Eu vou ganhar na mega sena e daí só vou ajudar os meus amigos grande. Nenenzinho não preciso ajudar, porque as tia vêm e levam para adoção. Já ajuda daí’.

Tais discursos serão detalhados adiante, na análise do conteúdo.

Em seguida, aparece a categoria "aproximar", com um percentual de 13,02\% no grupo I. Quando as crianças desse grupo aproximavam-se umas das outras, faizm-no para pedir algo ou mostrar um objeto. Nas observações, apareceram situações que confirmam esse dado, quando Bruninho se aproximou de Lucas e falou : "Olha meu carrinho"; ou quando Édson se aproximou de Márcio e pediu: "Dá pra mim essa pipa"?.

Observou-se que, no grupo II, esse comportamento alcançou $15,61 \%$ de freqüência e apenas $11,57 \%$ no grupo III. Constatou-se que nos grupos II e III, quando uma criança se aproximava da outra, fazia-o para oferecer ajuda ou para realizarem alguma tarefa juntas. Esses dados serão relatados durante a análise qualitativa de episódios de interação.

Outra categoria analisada foi o rir. Averiguou-se que as crianças do grupo I $(13,12 \%)$ e do grupo II $(11,12 \%)$ riam alto e esse riso era contagiante, pois, sempre que uma criança de qualquer grupo ria, provocava uma resposta semelhante no(s) parceiro (s). No grupo III, o rir aparece em menor proporção $(8,71 \%)$. Deve-se, contudo, ressaltar que, neste grupo, encontram-se apenas três participantes. Isto pode indicar que o comportamento "rir" para o grupo III não é menos relevante que o dos grupos I e II.

Por fim, constatou-se um percentual de 5,29\% no grupo I para a categoria "estender os braços". Nesse grupo, este comportamento provoca pegar no colo ou aproximar-se de outra criança. Verificou-se que os meninos do grupo I procuravam as meninas do grupo III ou os irmãos do grupo II quando desejavam colo. Raramente dirigiam-se às atendentes. No grupo II, o resultado com relação a estender o braço foi de $4,05 \%$. Aqui, o gesto indica um convite ao parceiro para brincar. Entre as crianças do grupo III, este comportamento atingiu $4,14 \%$. Neste grupo, o gesto é dirigido, com maior frequiência, às crianças do grupo I, em resposta ao "pedido de colo".

No geral, conclui-se que a categoria mais sugestiva encontrada nesta análise se refere a "contato físico". Entretanto, as pequenas diferenças encontradas não foram significativas. No referente ao "olhar", vale ressaltar que a troca de olhares possibilitava a aproximação ou acompanhava a separação, funcionando como um indicador de apego.

\section{Análise quantitativa e qualitativa de episódios de interação social em diferentes contextos}

A análise da interação entre as crianças foi feita a partir de um protocolo de observação, no qual os registros apresentavam episódios interacionais ocorridos durante a brincadeira, enquanto as crianças assistiam a televisão, faziam suas refeições, entre outros eventos (atividades de higiene, acompanhamento pedagógico, horário de visita). Também foram analisadas as interações sociais entre as crianças, quanto ao gênero.

A figura 2 apresenta os diferentes contextos em que ocorrem as interações sociais.

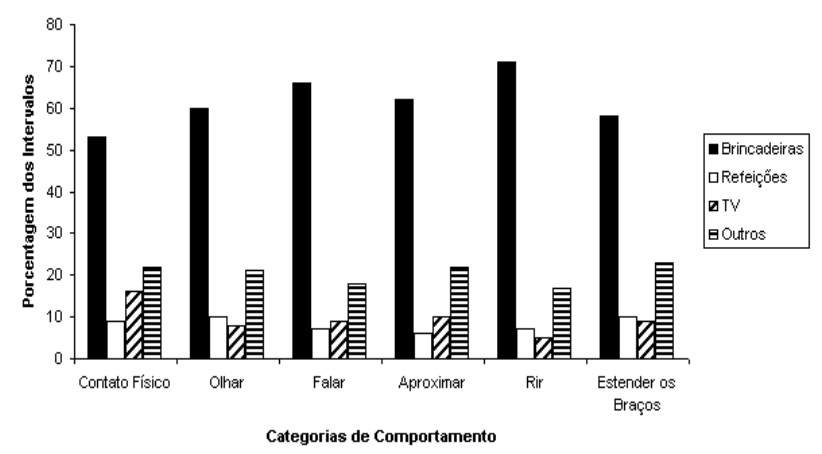

Figura 2. Porcentagem dos intervalos de observação despendido pelas crianças em cada uma das categorias de comportamento registradas durante diferentes contextos de interação social

Considerando-se a figura 2, verifica-se que, na amostra observada, as crianças passaram, em média, $62 \%$ do tempo envolvidas com brincadeira livre. É nesse momento que elas têm oportunidade de estabelecer suas interações, pois ficam longe da vigilância das atendentes e das represálias. Como não tinha um adulto dizendo o que elas tinham que fazer, as crianças corriam livremente pelo gramado e cooperavam umas com as outras espontaneamente.

Um exemplo disto eram as brincadeiras do faz-deconta e os jogos imaginativos. Observou-se que essas brincadeiras permitiam que todas as crianças participassem, não apresentando dificuldade de estar com o outro, dividir com o outro, uma vez que combinavam, sem discutir, os papéis que cada um interpretaria e os brinquedos que utilizariam nas respectivas brincadeiras, havendo assim, cooperação e consentimento mútuos. As crianças mais novas eram orientadas pelas crianças mais velhas em situações como brincar de pipa, em que os pequenos aprendiam que, para erguer a pipa, é preciso 
que um segure enquanto o outro vai puxando e soltando o barbante, até que a pipa ganhe altura para depois ser puxada contra o vento. É importante ressaltar que os meninos do grupo II confeccionavam as pipas e, nesse momento, planejavam e trocavam idéias no que dizia respeito ao tamanho, modelo, cores e tipo de rabiola. Alertavam os pequenos sobre o perigo de cerol e de a pipa ficar presa na fiação elétrica, conforme dados a seguir: “ Não pode passar cerol, porque corta o pescoço da pessoa e ela morre. Essa brincadeira é perigosa se tiver cerol. Se não tiver, é uma brincadeira legal e colorida” ou "Tinha que ter um pipódromo aqui no Abrigo, porque é perigoso soltar em qualquer rua, por causa dos fio. Se a pipa enrolar no fio, não pode tentar puxar senão fica preso e morre todo queimado. Daí é triste e perigoso. Tem que brincar certinho”.

\section{Análise das categorias temáticas}

Os resultados mostraram que a interação dialógica entre as crianças destaca-se como um aspecto relevante.

Constatou-se que a criança "fala alto" sobre seus planos interiores, seus desejos e suas ações. Dessa forma, foi definido um grupo temático, que se subdividiu em dez categorias e onze subcategorias, apresentadas no tabela abaixo:

Tabela 1. Falas das crianças registradas no diário de campo que foram divididas em categorias e subcategorias com base no seu conteúdo

\begin{tabular}{ll}
\hline Categorias & Subcategorias \\
\hline 1 - Baixo auto-estima & - Quando fala de si \\
& - Quando fala do outro \\
2 - Desejo de ir embora & 2.1 - Família biológica \\
& 2.2 - Família adotiva \\
3 - Sentimentos em relação à & 3.1 - Defesa \\
mãe biológica & 3.2 - Culpa \\
4 - Elogio & \\
5 - Ninguém liga para mim & \\
6 - Saudade & \\
7 - Preocupação com o irmão & 7.1 - Necessidades básicas \\
& $7.2 .-$ Situação de conflito \\
8 - Preocupação com os outros & 8.1 - Necessidades básicas \\
& 8.1 - Situação de conflito \\
9 - Segurança & 8.2 - Cuidado em troca de benefício \\
10 - Agressão Verbal & \\
\hline
\end{tabular}

\section{Categoria 1}

\section{Baixa auto-estima}

Esta categoria permitiu observar a imagem que as meninas participantes dessa pesquisa fazem de si mesmas e também a imagem que fazem de si, diante dos outros. Isto pode ser observado a partir das subcategorias:

\section{1 - Quando fala de si}

Através da fala das meninas (não foi observada esta fala no discurso dos meninos) verificou-se a formação de uma imagem pequena em relação ao valor e aparência que elas têm de si mesmas. Por exemplo:

\begin{abstract}
"Quando nós fizemo xixi na cama, fede tudo, daí nós ficamo pior ainda, umas fedida, porque só ficamo um pouquinho cheirosa quando tomamos banho" (Cátia).
\end{abstract}

\section{2 - Quando fala do outro}

Como pôde ser observado na fala de duas crianças, o discurso adotado é o de que o "outro" é sempre o melhor, o "outro" é aquele que consegue facilmente o que deseja. A diferença entre elas e o "outro" está relacionada à idade cronológica e à beleza física, como pode ser exemplificado nos discursos a seguir:

\begin{abstract}
“A Cláudia acha que passear na casa das família é ser adotado. Levar pra passear não é adotar, né tia? O Gustavo foi adotado, porque era nenenzinho e muito lindo" (Tereza).
\end{abstract}

\section{Categoria 2}

\section{2. $O$ desejo de ir embora}

A categoria exposta acima revela que o desejo das crianças participantes desse estudo, com exceção das meninas do grupo III, é ter uma família, e que elas não fazem exigência no que diz respeito aos futuros pais, pois pedem às pessoas que as visitam que as levem para suas casas. Isto pode ser comprovado nas subcategorias em destaque:

\section{1 - Família biológica}

Nesta subcategoria, ficou evidente o desejo das crianças de voltar para a família de origem, quando recebiam a visita da mãe biológica. Esses argumentos apareceram de maneira mais frequiente no grupo I, como, por exemplo:

\footnotetext{
“A minha mãe vai pedir pro juiz pra ela me levar pra casa com ela. Se ele é bom, ele vai deixar eu ir com a minha mãe" (Daniel).
}

Em relação ao desejo de voltar para a família biológica é relevante comentar que esse desejo vem acompanhado da preocupação para com os irmãos que estão no abrigo também. A seguir, apresentamos uma das falas que confirmam estes dados.

"Quando nós for embora, a mãe vai contá historinha pra mim e pros meus irmãos" (Lucas). 


\section{2 - Família adotiva}

O desejo de ir embora reflete também o desejo de ser adotado(a). Os argumentos foram expressos por crianças de todos os grupos. Algumas relacionam a mãe adotiva àquela pessoa boa, disposta a cuidar e amar. Esses sentimentos, nas crianças dos grupos I e II, geram expectativa em relação ao futuro. Veremos abaixo um dos exemplos mais representativos:

\footnotetext{
"Quando eu ser adotada, vou ter uma mãe que gosta de criança, daí não vou mais apanhar" (Cláudia).
}

\section{Categoria 3}

3. Sentimentos em relação à mãe biológica

Essa categoria abrange duas subcategorias:

\subsection{Culpa}

Algumas crianças do grupo II e do grupo III apresentaram um sentimento negativo em relação às suas mães biológicas. Os argumentos aqui colocados apontam a mãe como a culpada pelo fato de hoje viverem no abrigo. É interessante ressaltar que não houve registro sobre a figura do pai no discurso dos participantes:

\begin{abstract}
"O Caco quer ir embora porque ele era o queridinho da mamãe. Pra ele é fácil voltar pra casa, porque aquela bruxa dizia que tudo era culpa minha. E tudo o que aconteceu de errado era culpa dela. Ela me mandava pro semáfaro pedir esmola. Aqui no abrigo eu tenho amigos e gosto mais deles do que dela" (Sofia).

"Bêbada e vagabunda é tudo igual. A mãe largou nós aqui. Acho que ela tá presa. Por mim, nem ligo. Melhor ficar com os meus amigos aqui, mesmo"(Sofia).
\end{abstract}

\section{2 - Defesa}

Aqui, as manifestações refletem a procura pela mãe biológica. Pôde-se perceber que as crianças do grupo I são as que mais alimentam a expectativa de voltar para a família de origem. Em seus discursos não aparecem componentes emocionais, como o ressentimento, a raiva e a culpa pelo fato de viverem em um abrigo.

Ao ouvirem as crianças do grupo II e III acusando a mãe pelo motivo de terem sido abrigadas, defendem as suas mães da seguinte forma:

\footnotetext{
"Tia, a minha mãe bebe, mas ela não quer dá nóis. Ela não é vagabunda como a minha irmã diz" (Daniel).

"Cala a boca, Tereza. Eu gosto de ti, mas não fala coisa ruim da minha mãe" (Lucas).
}

\section{Categoria 4}

\section{Elogio}

Presente também na fala das meninas do grupo III estiveram os elogios ao cuidarem das crianças do grupo I. Estes elogios aconteciam, principalmente, durante as refeições e a higienização, como ilustram os exemplos a seguir:

Come tudo pra ficar mais bonita ainda, meu anjo (Cátia).

"Nossa! Como o André é cheiroso... que banho gostoso"! (Sofia).

De forma semelhante, os irmãos menores tecem elogios aos irmãos maiores, deixando transparecer admiração e orgulho. Em algumas falas podemos observar estes sentimentos:

"Ele é forte, tia. O Caco tem bastante força" (Daniel).

"A Carolaine é que foi corajosa! Ela teve coragem de fugir. Ninguém teve essa coragem" (Édson).

\section{Categoria 5}

\section{Ninguém liga pra mim}

Em relação à temática "ninguém liga pra mim", observou-se um conteúdo emocional negativo. As crianças, de ambos os grupos, demonstraram insatisfação em relação aos cuidados recebidos. Tal relato reflete a idéia de rejeição e injustiça:

"Tia, conta uma historinha pra nós, né? Ninguém conta historinha pra nós. A gente fica pedindo, mas ninguém liga e nós achamo legal contar historinha" (Eduardo).

\section{Categoria 6}

\section{Saudade}

A saudade aparece, para as crianças, principalmente relacionada à figura dos amigos que foram adotados ou voltaram para a família de origem, ou à figura dos irmãos que vivem em outros abrigos. Os exemplos descritos abaixo demonstram esta categoria:

"Eu não queria que a Clarinha fosse adotada, porque daí nós vamo sentir muita saudade, igual como nós temo saudade da Silvinha" (Sofia).

"Eu to mesmo é com saudade da minha irmã que tá no outro abrigo. Queria ir só lá dormir com ela" (Rodrigo). 


\section{Categoria 7}

\section{Preocupação com o irmão}

Esta categoria está relacionada com a maneira como os irmãos mais velhos se preocupam com os irmãos mais novos. Foram identificadas como subcategorias:

\subsection{Necessidades básicas}

A subcategoria necessidades básicas aparece durante o banho e no que diz respeito à alimentação. As meninas, principalmente as dos grupos II e III, controlam esses eventos e sempre que têm oportunidade demonstram cuidado e atenção para com os irmãos, evidenciando a importância que dão à vida deles. Preocupação quanto às necessidades básicas aparecem nos seguintes exemplos:

"Vem, Daniel. Vai tomar banho pra ficar limpo e ficar com saúde" (Sofia).

"Ela é minha irmã. Eu cuido dela, sim e é bem bacana. Quando ela tem fome eu é que levo comida, visse?" (Tereza).

\subsection{Situação de conflito}

Constatou-se a preocupação com o irmão em situações conflitantes, tais como: problemas na hora de dormir, brincadeira agonística e brigas. Este sentimento é identificado na seguinte fala:

Joga em mim esse trabesseiro, então, porque o meu irmão é pequeno, seu covarde! Brincadeira mais besta é essa! Se tu quiser fazer ele chorar, tem que bater em mim primeiro, visse? E não chama ele de burro. É bom deixá ele em paz, senão quebro tua cara. Vai brincá direito (Felipe).

\section{Categoria 8}

\section{Preocupação com os outros}

Os resultados revelaram também que a preocupação apresentada pelas crianças não se limita aos irmãos, mas se estende aos amigos do abrigo. Os dados demonstram que, além das subcategorias necessidades básicas e situações de conflito para esta categoria, foi identificada uma terceira subcategoria, que diz respeito ao cuidado em troca de benefício.

\subsection{Necessidades básicas}

As informações obtidas no diário de campo permitiram compreender que as crianças cuidam uma das outras, havendo a prática de uma "espécie de maternagem" por parte das meninas do grupo III em relação aos meninos do grupo I, como foi possível averiguar neste discurso:
"Vem cá, Bruninho. Eu dou bolachinha pra ti, querido. Tem que comer tudinho" (Tereza).

\subsection{Situação de conflito}

De acordo com os dados, verificou-se o zelo pelo bem-estar que as crianças têm umas com as outras. Foram observados momentos de impasse e conflito, como pode ser comprovado abaixo:

"Nós temo que ficar tudo de bem. Assim é melhor pra nós, porque ficamo melhor se somo tudo amigos" (Daniel).

"A tia podia levar nós tudo pra praia. Tá supercalor e tem que ir todo mundo, porque todo mundo aqui está com calor. Todo mundo aqui gosta de praia e quem não for vai ficar chorando" (Cláudia).

\subsection{Cuidado em troca de benefícios}

Aqui, as crianças manifestam carinho e preocupação por outras crianças deixando claro um interesse particular na figura do amigo, como demonstra o argumento abaixo:

Eu fico preocupada com a Carol. Ela fugiu e eu fico preocupada. Ela faz falta aqui e ela tinha bastante esmalte (Sofia).

\section{Categoria 9}

\section{Segurança}

Em relação à categoria segurança, verificou-se que ela foi identificada no discurso das crianças do grupo I quando se referiam aos irmãos mais velhos. Nesse caso, apareceram referências de que o(a) irmão(ã) mais velho(a) é aquela pessoa forte, que cuida, protege e guarda:

"Era melhor quando eu tava com a minha irmã no outro abrigo, porque ninguém batia em mim, lá” (Rodrigo).

\section{Categoria 10}

\section{Agressão verbal}

Outra forma de comunicar o cuidado entre os irmãos, visando defendê-los em situação de conflito, é a "agressão verbal". Entretanto, essa conduta não implica inimizade e violência física, pois, à medida que resolvem o problema, voltam a brincar e ficar juntos. Deve ser resultante da falta de estratégias para organizar respostas melhores aos ataques sofridos, e esse comportamento reflete o apego que existe na relação fraterna. A esse respeito verificou-se que, após o discurso, o irmão mais velho permanecia furioso 
durante certo tempo, buscando a companhia dos outros irmãos. Como exemplo, citamos:

Pára, seu trouxa. A minha irmã não parece nenhum bicho morto de fome, seu palhaço (Cátia).

\section{DISCUSSÃO DOS RESULTADOS}

A partir dos resultados, pode-se afirmar que as crianças institucionalizadas que participaram deste estudo mantêm relações afetivas umas com as outras, apresentando responsividade e comportamento similar ao referenciado por Bowlby (1984), em relação ao apego estabelecido entre a díade mãe-bebê. Os dados apresentados neste estudo revelaram alguns aspectos relevantes, dentre os quais destacaremos: o apego entre irmãos e com os pares; o apego no contexto da brincadeira e apego x representação da família.

\section{O apego entre irmãos e com os pares}

Os resultados revelam, observando-se a figura 1, que, na interação criança-criança, todas as categorias estiveram representadas, em maior ou menor grau. $\mathrm{O}$ relacionamento entre os irmãos e os pares participantes do estudo foi caracterizado principalmente pela ênfase no contato físico e busca constante pela presença do outro.

Foi possível reconhecer na interação com os pares que as meninas do grupo III são sensíveis e responsivas aos sinais e comunicações dos meninos do grupo I. Tais meninas manifestaram comportamentos de cuidado e proteção em relação aos meninos do grupo I. Tal comportamento é semelhante ao apresentado pelas mães em relação aos filhos, referenciado por Bowlby (1989). Nesta discussão, é importante ressaltar que, nas relações de afeto e de cuidado, os papéis desempenhados pelos irmãos mais velhos e pelos pares assumem um significado muito específico e de grande importância para o desenvolvimento social, afetivo e cognitivo das crianças menores. Este dado demonstra que, após a separação da família, um amigo do abrigo passa a ser uma figura de apego.

Outra indicação que os dados fornecem é a de que os irmãos mais velhos demonstram preocupação com os irmãos mais novos. Uma característica marcante, observada no discurso dos irmãos mais velhos, é a agressão verbal, como pode ser visto no quadro das categorias temáticas, quando se trata de defender o irmão mais novo. Sobre isso, Ferreira e Mettel (1999), em um estudo realizado sobre a interação entre irmãos em situação de cuidados formais, salientam que o filho indicado como o responsável pelo cuidado dos pequenos desempenhou a tarefa com facilidade, demonstrando manter o controle sobre os irmãos menores, protegendo-os em situações de risco, sem usar agressão física.

Este estudo demonstrou que uma rede de apoio social e afetiva é fundamental para as crianças, uma vez que lhes possibilita condições de se desenvolver adequadamente. É importante ressaltar que tais crianças demonstraram-se resilientes, e isso pode estar relacionado ao fato de poderem contar com um conjunto de fatores de proteção, incluindo-se laços afetivos positivos com os irmãos mais velhos que vivem no mesmo abrigo ou com os funcionários da instituição. Não se pode descartar a hipótese de as crianças encontrarem suporte emocional fora do abrigo - por exemplo, com os professores ou colegas das creches e escolas que frequientam, ou com pessoas que são voluntárias e visitam freqüentemente o abrigo. Nesse sentido, tal fenômeno ocorre devido à rede de apoio, no modelo apresentado por Britto e Koller (1999), quando afirmam que existe um movimento de pessoas que se incluem e se excluem das redes de apoio de outras no decorrer da vida.

\section{$O$ apego no contexto da brincadeira}

Como se pôde constatar na apresentação dos resultados, através de uma análise qualitativa, na interação criança-criança predominou a brincadeira, visto que a rotina do abrigo para as crianças participantes deste estudo caracteriza-se, em sua maior parte, por brincadeiras livres. Este mesmo resultado foi observado por Carvalho (2002), cujo estudo verificou que, no orfanato, as crianças, em intensa convivência umas com as outras, dispõem de longos períodos para recreação livre e têm mais oportunidades para se envolver com brincadeiras.

Um dado favorável, na análise do apego no contexto da brincadeira, foi o fato de não haver excluídos da brincadeira, ou seja, constatou-se que nenhuma criança ficou isolada das brincadeiras do grupo, por demonstrar dificuldade de estabelecer relações com as demais crianças ou porque seu desempenho fosse rejeitado pelo grupo. Dessa forma, os resultados deste estudo possibilitaram verificar que a brincadeira proporciona o exercício das relações de apego entre as crianças pesquisadas. É no abrigo que elas começam $o$ processo de aprendizagem, descobrindo a si mesmas e descobrindo os outros, pois muitas das primeiras experiências com pessoas da mesma idade e vivência aconteceram na instituição. Ao mesmo tempo em que elas brincam com as outras crianças, percebem que não estão sozinhas e não são 
as únicas que vivem em situação de abrigo. Assim, começam a conviver em grupo e a (re)significar seus mundos, reciclar suas emoções e reinventar suas realidades, confirmando que brincar é essencial à saúde física, emocional e intelectual do ser humano (Kishimoto, 1996).

Ao brincarem, as crianças deixavam transparecer um pouco da sua história de vida e das situações vivenciadas no abrigo. Enquanto brincavam, buscavam por contato físico e riam constantemente umas com as outras. Nas brincadeiras, envolviam-se de forma compenetrada e, além dos brinquedos utilizados, as crianças menores assumiam papéis designados pelas crianças maiores. Na brincadeira de "casinha", por exemplo, as meninas do grupo III eram sempre "mães" e os meninos do grupo I, os "filhinhos", na maioria das vezes, "bem-cuidados e amados". Os dados indicam que não houve a reprodução de experiências traumáticas ou do ambiente no qual elas ocorreram. $\mathrm{O}$ trabalho de Mello (1999), com crianças vítimas de violência doméstica, contém conteúdos expressos no brincar semelhantes a esse, demonstrando que as crianças não traduziram a realidade das violências que sofreram.

Podemos concluir que brincar é fundamental para a vida destas crianças. Por meio das brincadeiras, elas desenvolvem a sociabilidade e demonstram o afeto que sentem umas pelas outras. Para estas crianças, brincadeira não é apenas diversão. Brincando, elas expressam sentimentos, revelam o seu interior, interpretando o mundo que as cerca, à sua própria maneira. Elaboram situações desprazerosas da sua vivência, buscando soluções, a fim de torná-las prazerosas (Kishimoto, 1996).

Diante disso, sugere-se aos profissionais que lidam com as crianças que vivem em situação de abrigo ficarem atentos ao comportamento destas durante a brincadeira, pois tal investigação pode fornecer subsídios para intervenções que visam melhorar a qualidade da interação social destas crianças, uma vez que a pesquisa evidenciou uma vinculação positiva entre os pares no contexto da brincadeira.

\section{Apego x representação da família}

De acordo com o agrupamento dos núcleos temáticos, verificou-se que as falas da maioria das crianças expressam o desejo de ter uma família. Algumas crianças revelaram a vontade de voltar para seus lares de origem, enquanto outras esboçaram idéias relacionadas à adoção. Entretanto, também ocorreu as mesmas crianças desejarem ora voltar para a família biológica ora ser adotadas. Em face disso, pode-se dizer que as crianças participantes deste estudo se debatem entre as duas imagens de família.

Nos depoimentos dos participantes, foi possível observar que o pai é figura ausente na vida destas crianças. Para Weber (1999), este fato pode dever-se ao fato de que a maioria das crianças que chega às instituições é pertencente a famílias monoparentais (nas quais somente a mãe e os irmãos estão presentes).

Sobre a figura materna, observou-se que a mãe ocupou um lugar privilegiado no discurso dos meninos participantes desta pesquisa. No entanto, a visão que eles têm da mãe é mais idealizada do que real, atribuindo a ela a função de tirá-los do abrigo e leválos para casa, para serem cuidados e amados. Percebese, também, que alguns meninos dos grupos I e II defendem suas mães quando ouvem alguém criticá-las. Alguns acabam justificando a atitude da mãe, sentindoa como vítima, e acreditam na idéia de que elas nunca desistirão do pátrio poder e, portanto, em breve, virão buscá-los. Sobre o desenvolvimento do amor materno, vale lembrar Badinter (1985), o qual, ao fazer referência ao amor materno, assinala que é um sentimento humano e, como tal, é incerto, frágil, imperfeito, podendo sofrer mudanças com a época, com o tipo de sociedade e com as condições culturais, como qualquer sentimento.

Outro aspecto que merece ser destacado diz respeito ao desejo que algumas crianças manifestaram de serem adotadas. É importante ressaltar que as crianças não apontam características para as famílias substitutas. Do contrário, dados como os da pesquisa realizada por Weber (1999), sobre os desejos e expectativas de pessoas cadastradas para adoção, em Curitiba, Paraná, apresentam o desejo dos adotantes, ao traçarem o perfil de crianças a serem adotadas, como: sexo feminino, cor branca, idade inferior a 3 anos. Tais dados coincidem com a fala da menina Sofia, observada na presente pesquisa, ao dizer: "queria ser adotada, mas já tenho 9 anos e ninguém adota menina grande”.

De forma geral, no discurso das crianças, ficou evidente o desejo e a necessidade de manter o vínculo com suas mães, com suas famílias de origem ou famílias substitutas. No entanto, foi possível observar o apego entre as crianças pesquisadas, constatado através do cuidado que os irmãos mais velhos apresentavam em relação aos irmãos mais jovens e entre os pares.

\section{CONSIDERAÇÕES FINAIS}

Uma vez reconhecida a importância do apego e sua influência sobre o desenvolvimento infantil, observa-se a falta de literatura sobre o tema relacionado às crianças que vivem em situação de abrigo no contexto brasileiro. 
No Brasil, o abandono e a realidade de crianças nas ruas são fenômenos bastante marcantes. Após a separação de suas famílias, estas crianças tentam encontrar outras figuras de apego em diferentes situações. Nesse sentido, seria importante desenvolver estudos nesta área, a fim de observar, ouvir e interpretar a fala das crianças. Essas atividades teriam como objetivo fazer uma análise cuidadosa da realidade vivenciada e poderiam ajudar na elaboração de programas psicológicos e sociais que nos conduzirão a formas de atuação que favoreçam a efetivação dos direitos previstos pelo Estatuto da Criança e do Adolescente.

\section{REFERÊNCIAS}

Badinter, E. (1985). Um amor conquistado: o mito do amor materno. (W. Dutra, Trad.). Rio de Janeiro: Nova Fronteira. (Originalmente publicado em 1980).

Bardin, L. (1991). Análise de conteúdo. Lisboa: Edições 70.

Bowlby, J. (1984). Separação: angústia e raiva. (L. Hegenber, O. da Mota \& M. Hegenberg, Trad.). São Paulo: Martins Fontes. (Originalmente publicado em 1973).

Bowlby, J. (1989). Uma base segura: aplicações clínicas da teoria do apego. (S. Monteiro, Trad.). Porto Alegre: Artes Médicas. (Originalmente publicado em 1980).

Bowlby, J. (1990). Apego e perda. (2 ed., A. Cabral, Trad.). São Paulo: Martins Fontes. (Originalmente publicado em 1969).

Britto, R. C. \& Koller, S. H. (1999). Desenvolvimento humano e redes de apoio social e afetivo. Em A. M. Carvalho (Org.), $O$ mundo social da criança: natureza e cultura em ação (pp. 115129). São Paulo: Casa do Psicólogo.

Carvalho, A. M. (2002). Crianças institucionalizadas e desenvolvimento: possibilidades e desafios. Em E. R. Lordelo, A. M. A. Carvalho \& S. H. Koller (Orgs.), Infância brasileira e contextos de desenvolvimento (pp. 19-44). São Paulo: Casa do Psicólogo/ Salvador: Editora da Universidade Federal da Bahia.

ECA - Estatuto da Criança e do Adolescente. Lei 8.06 de 13.07.90.

Ferreira, E. A. P. \& Mettel, T. P. L. (1999). Interação entre irmãos em situação de cuidados formais. Psicologia: Reflexão e Crítica, $12,133-146$.
Infante, F. (2001). La resiliencia como processo: uma revisión de la literatura reciente. Em A. Melillo, \& E. N. S. Ojeda (Orgs.), Resiliencia: descubriendo lãs proprias fortalezas (pp. 31-54). Buenos Aires: Paidós.

Kishimoto, T. M. (1996). Jogos tradicionais infantis: o jogo, a criança e a educação. Petrópolis (RJ): Vozes.

Klaus, M. H., Kennell, J. H. \& Klaus, P. H. (2000). Vínculo: construindo as bases para um apego seguro e para a independência. (M. R. Hofmeister, Trad.). Porto Alegre: Artes Médicas. (Originalmente publicado em 1995).

Lebovici, S. (1987). O bebê, a mãe e o psicanalista. Porto Alegre: Artes Médicas.

Martin, P. \& Bateson, P. (1986). Measuring behaviour. Cambridge: Cambridge University Press.

Mello, A. C. M. P. C. (1999). O brincar de crianças vítimas de violência física doméstica. São Paulo. Dissertação de Mestrado, Instituto de Psicologia da Universidade de São Paulo, São Paulo.

Miller, S. A. (1998). Developmental research methods. (2 ${ }^{\mathrm{a}}$ ed.). New Jersey: Prentice Hall Inc.

Newcomb, M. (1990). Social support and personal characteristics: a developmental and interactional perspective. Journal of Social and Clinical Psychology, 9, 54-68.

Oppenheim, D., Koren-Karie, N. \& Sagi, A. (2001) Mothers' emphatic understanding of their preschoolers' internal experience: relations with early attachment. International Journal of Behavioral Development, 25, 16-26.

Rizzini, I. (1997). O século perdido. Rio de Janeiro: Amais.

Rossetti-Ferreira, M. C. (1986). Mãe e criança, separação e reencontro: observação de grupo. São Paulo: Edicon.

Rutter, M. (1997). Psychosocial resilience and protective mechanisms. American Journal Orthopsychiatry, 57, 316-331.

Tyler, F. (1984). El comportamiento psicosocial, la competência psicosocial individual y las redes de intercambio de recursos como ejemplos de psicologia comunitária. Revista Latino-Americana de Psicologia, 16, 77-92.

Weber, L. N. D. (1999). O que sentem as crianças institucionalizadas em relação a seus pais biológicos e ao futuro? [Resumo]. Em Sociedade Brasileira de Psicologia (Org.), Caderno de Resumos da XXVI Reunião Anual de Psicologia da Sociedade Brasileira de Psicologia (p.179). Ribeirão Preto, SP: SBP.

Recebido em 20/02/2004 Aceito em 30/06/2004

Endereço para correspondência: Diuvani Tomazoni Alexandre. Instituto Fayal de Ensino Superior (IFES). Av. Adolfo Konder, 2000, São Vicente, CEP 88303-000, Itajaí-SC. E-mail: diuvani@bol.com.br 